\title{
SENSITIVE RESONANT GAS SENSOR OPERATING IN AIR WITH METAL ORGANIC FRAMEWORKS COATING
}

\author{
N. Jaber, S. Ilyas, O. Shekhah, M. Eddaoudi, and M. I. Younis \\ King Abdullah University of Science and Technology, Thuwal, Saudi Arabia
}

\begin{abstract}
We report a practical resonant gas sensor that is uniformly coated with metal organic frameworks (MOFs) and excited near the higher order modes for a higher attained sensitivity. The resonator is based on an electrostatically excited clamped-clamped microbeam. The microbeam is fabricated from a polyimide layer coated from the top with $\mathrm{Cr} / \mathrm{Au}$ and from the bottom with $\mathrm{Cr} / \mathrm{Au} / \mathrm{Cr}$ layer. The geometry of the resonator is optimized to reduce the effect of the squeeze film damping, thereby allowing operation under atmospheric pressure. The electrostatic force electrode is designed to enhance the excitation of the second mode of vibration with the minimum power required. Significant frequency shift $(\mathrm{kHz})$ is demonstrated for the first time upon water vapor, acetone, and ethanol exposure due to the MOFs functionalization and the higher order modes excitation. Also, the adsorption dynamics and MOF selectivity is investigated by studying the decaying time constants of the response upon gas exposure.
\end{abstract}

\section{KEYWORDS}

Gas detection, electrostatic actuation, selectivity and resonators.

\section{INTRODUCTION}

Micro/nano resonators have shown promising results for the detection of gasses and minute masses [1-13]. Enhancing the sensitivity, reliability, and reducing the power of electrostatically actuated resonant gas sensors have been the subject of extensive research in the past two decades $[14,15]$. Electrostatic actuation is the most commonly used method due to the low power consumption, ease of fabrication, and integration with CMOS circuits [16]. However, most of the electrostatically actuated resonators for gas sensing need to be operated under controlled environmental conditions and at low pressure to reduce the effect of squeeze film damping and obtain a high signal-to-noise ratio [17]. One solution, which requires complex circuit design, is to use positive and amplified feedback signal from the resonator oscillation velocity to enhance the quality factor [18]. Another approach is to introduce perforations in the resonator surface with careful design of the holes size and shape to minimize the damping effect [19].

To improve sensitivity, different dynamical principles have been utilized, such as bifurcation points and pull-in instabilities [20-22], weakly coupled resonators [23-26], and the coupling between bending and torsional modes [27]. The sensitivity can be further improved by reducing the resonator size. However; shrinking the size reduces the area available for functionalization and requires more controlled environmental condition for sensing. Alternatively, operating the resonator near the higher order modes can improve sensitivity [28, 29]. To excite the higher order modes with high amplitudes above the noise level and with the minimum required power, partial electrode configurations have been proposed [30], where the lower electrode is designed to enhance and trigger the desired mode. Also, an increase in the quality factor is reported near the higher order modes, which is desirable for ultra-sensitive gas sensors [31, 32].

The ability to selectively detect specific gasses under ambient conditions represents a constant technological challenge. Functionalizing the resonator surface gives the capability for selective detection. To detect a particular gas, resonators are coated with a thin film that has an affinity to a specific gas due to the chemical and/or physical interaction [33-35]. Gold coated resonators are proposed for mercury detection in [36]. Depending on the gold coating profile whether uniform layer or isolated islands, different responses have been reported. Functionalization with zeolitic imidazolate framework (ZIF), which has nanoporous structure, is proposed for detecting $\mathrm{CO}_{2}$. The selectivity of the ZIF coating to different gasses is demonstrated by studying the adsorption time constant for IPA and $\mathrm{CO}_{2}$ [23]. A cantilever coated with ZIF is investigated for detecting nitrotoluene, which is an explosive related molecule [4]. In [12], an artificial nose is developed by coating an array of eight cantilevers with different polymers for selective gas sensing.

Metal-organic frameworks (MOFs) are porous materials composed of organic and inorganic materials with exposed inner chemical functionality and large surface area that can be easily tuned, functionalized, and engineered to selectively detect a specific gas [37, 38]. Resonators coated with MOFs are proposed for detecting a wide range of gasses, including volatile organic compounds [39], humidity [40], and $\mathrm{H}_{2} \mathrm{~S}$ [41].

In this paper, we present an electrostatically actuated resonator, excited near the second mode of vibration, and operated under ambient pressure and temperature. Also, the sensor can perform switching upon exceeding a threshold value. The resonator is functionalized with MOFs to further maximize its sensitivity when exposed to vapors.

\section{FABRICATION}

In this paper, we study and characterize clampedclamped microbeam resonators electrostatically actuated using a lower electrode that spans half of the beam length to enhance the excitation of the second mode of vibration 
[30]. To reduce the effect of squeeze film damping and operate the resonator in air, the microbeam width is reduced to $20 \mu \mathrm{m}$, which is the minimum width imposed by the fabrication process. The microbeam is fabricated using the process developed in [42] and composed of a 4.2 $\mu m$ polyimide layer coated from top with $\mathrm{Cr} / \mathrm{Au}$ layer. $\mathrm{The} \mathrm{Cr} / \mathrm{Au}$ layer acts as a hard mask that protects the beam during the reactive ion etching and defines the microbeam dimensions. The upper electrode is formed by coating the beam from the bottom with $\mathrm{Cr} / \mathrm{Au} / \mathrm{Cr}$ of thicknesses $50 / 200 / 50 \mathrm{~nm}$. The lower electrode spans half of the beam length to optimize the excitation of the second mode shape. The two electrodes are separated by $3.3 \mu \mathrm{m}$ air gap. In addition to its chemical and thermal stability, the polyimide has a low modulus of elasticity $(8.5 \mathrm{GPa})$, which significantly reduces the voltage required to excite the resonator compared with silicon $(160 \mathrm{GPa})$.

The microbeam surface is functionalized with a $\mathrm{COOH}$-terminated layer by immersing the chip in an ethanolic solution of 16-mercaptohexadecanoic acid for 24 hours [43-45]. Before releasing the microbeam, a uniform MOF layer is grown using a layer-by-layer approach, by dipping the unreleased chip in copper acetate metal precursor ethanolic solution and organic ligand (terephthalic acid) ethanolic solution for two and three minutes, respectively. The process is repeated for 12 cycles where the chip is rinsed with ethanol every cycle [40]. Fig. 1 shows an optical and schematic of the MOF coated microbeam.

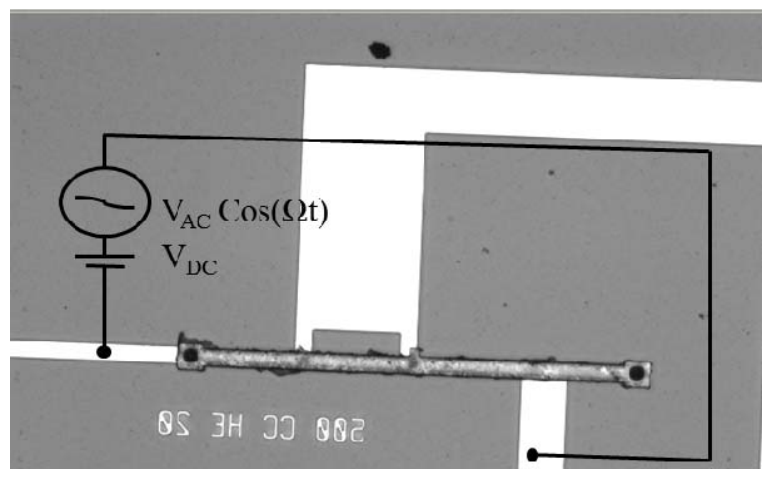

(a)

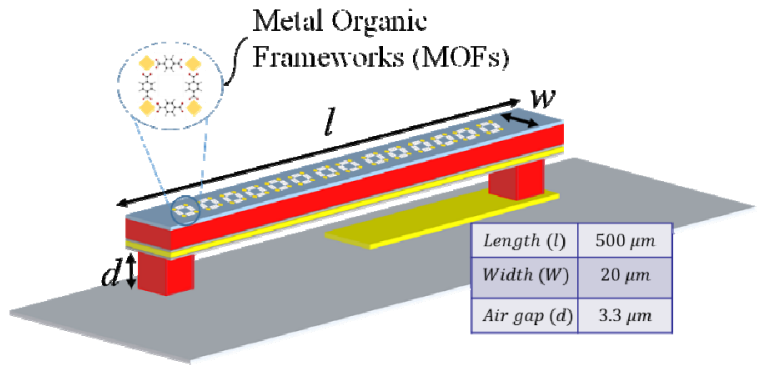

(b)

Fig. 1. (a) Top view picture of the fabricated microbeam with the MOF coating. (b) Schematic view of the clamped-clamped microbeam with the lower half electrode indicating the beam dimensions.

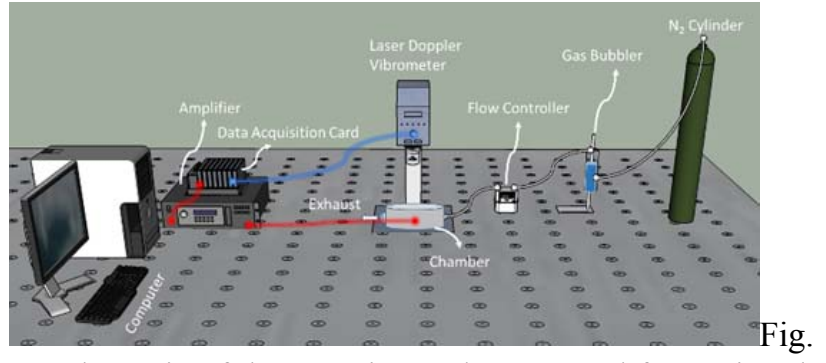

2. Schematic of the experimental setup used for testing the device.

The experimental setup is shown in Fig. 2. The microbeam is electrostatically actuated by a data acquisition card connected to an amplifier, which provides actuation signals of wide range of frequencies and amplitudes. A laser Doppler vibrometer (MSA-500) is utilized to monitor the beam response and track the shift in the amplitude of vibration due to gas exposure. The microbeam is placed into a chamber connected to a gas bubbler. The gas flow into the chamber is controlled using the flow controller.

\section{Natural frequencies}

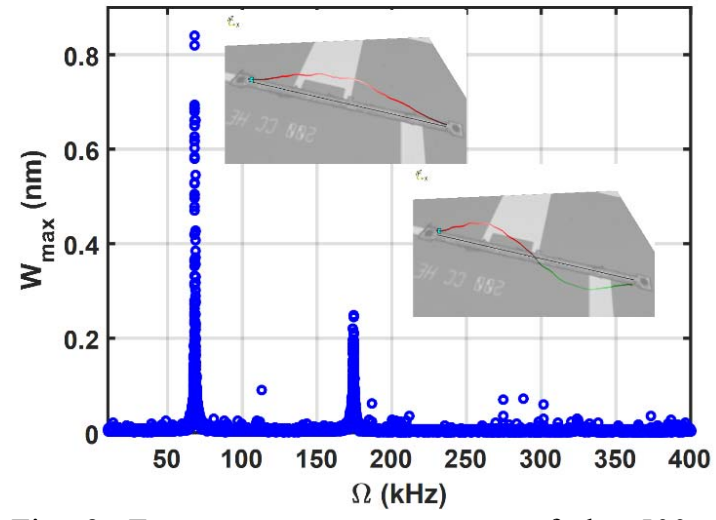

Fig. 3. Frequency response curve of the $500 \mu \mathrm{m}$ long microbeam to a white noise excitation at $V_{D C}=15 \mathrm{~V}$ and $V_{A C}=10 \mathrm{~V}$. Insets: The corresponding mode shapes.

To reveal the resonance frequencies, we experimentally actuate the device with a white noise signal. The vibration at different points along the beam is recorded to extract the frequency response curve and the corresponding mode shape, as depicted in Fig. 3. The measured mode shapes, insets of Fig. 3, match the clamped-clamped microbeam mode shape without any distortion or irregularities, which confirms the uniformity of the coating layer on the resonator surface.

\section{Frequency response curves}

\section{CHARACTERIZATION}




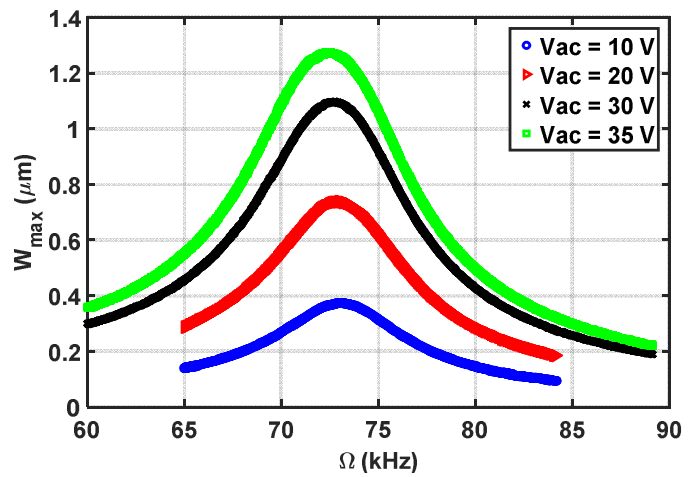

(a)

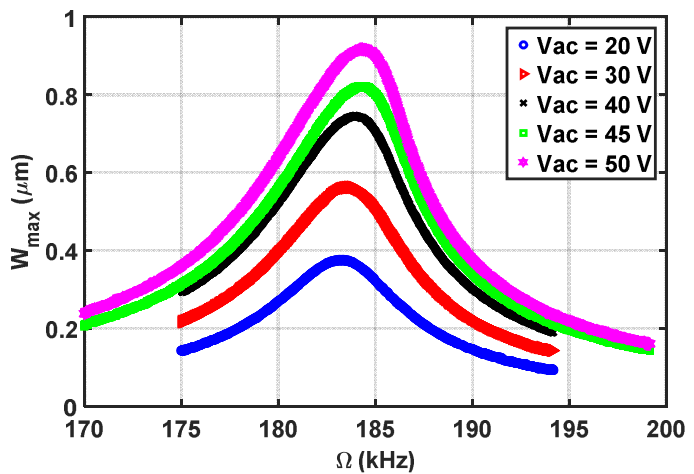

(b)

Fig.4. Frequency response curves at $V_{D C}=30 \mathrm{~V}$ and different $V_{A C}$ excitation near (a) the first mode, (b) the second mode.

Next, we experimentally investigate the frequency response of the microbeam near the first and second mode of vibration. The microbeam is excited using the data acquisition DAQ card, and the vibration is detected using the laser Doppler vibrometer. The excitation signal is composed of an AC signal $V_{A C}$ superimposed to a $\mathrm{DC}$ signal $V_{D C}$. The measurement is performed by focusing the laser at the mid-point for the first mode measurements and quarter of the beam length for the second mode measurement. Then, the frequency response curve is generated by sweeping the frequency $\Omega$ of the AC source near the mode of interest and taking the steady state maximum amplitude of the motion $W_{\max }$. Figure 4 shows the frequency response near the first $(72.5 \mathrm{kHz})$ and second $(184.2 \mathrm{kHz})$ modes of vibration for different $\mathrm{AC}$ loadings.

\section{Sensor calibration}

To quantify the amount of adsorbed gas, different methods have been utilized in the literature, such as tracking the frequency shift by implementing a phaselocked loop circuit, monitoring the gain or phase change for a fixed frequency excitation, or measuring the change in the quality factor (Q). The most conventional method is to monitor the frequency shift using the phase locked loop (PLL). This method is adequate for high $\mathrm{Q}$ resonators. For low $\mathrm{Q}$ resonators, designing and implementing the PLL circuit becomes challenging and complicated. In this case, another method is recommended, in which the resonator is excited near the resonance frequency, and the amplitude change due to gas exposure is recorded. Then, the amplitude change is calibrated into a frequency shift, which is used to calculate the amount of the adsorbed gas [46]. Figure 5 shows the frequency response and the calibration formula near the first and second mode of vibration of the $500 \mu \mathrm{m}$ long microbeam. The operating point is chosen close to the peak of the response curve, i.e., at $72.5 \mathrm{kHz}$ near the first mode and $184.2 \mathrm{kHz}$ near the second mode. As vapor is being absorbed on the resonator surface, the amplitude decreases following the right branch of the response. This decrease is transformed into frequency shift by using the slope, as shown in each plot. The responsivity of the sensor is given by

$\mathfrak{R}^{-1}=\left|\frac{d m}{d f}\right|=\frac{2 m_{\text {eff }}}{f_{\text {res }}}$

where $m_{e f f}$ is the effective mass of the clamped-clamped beam defined as $m_{\text {eff }}=\alpha m$ where $\alpha=0.3965$ for the first mode and $\alpha=0.4390$ for the second mode [47]. The mass $m$ of the microbeam was calculated from the geometrical dimensions and the material properties $m=128.09 \mathrm{pg}$. From Eq. (1) we found that the responsivity of the resonator near the first and second mode equals to $\mathfrak{R}_{1 s t}^{-1}=1.5 \mathrm{fg} / \mathrm{Hz}$ and $\mathfrak{R}_{2 n d}^{-1}=0.64 \mathrm{fg} / \mathrm{Hz}$, respectively.

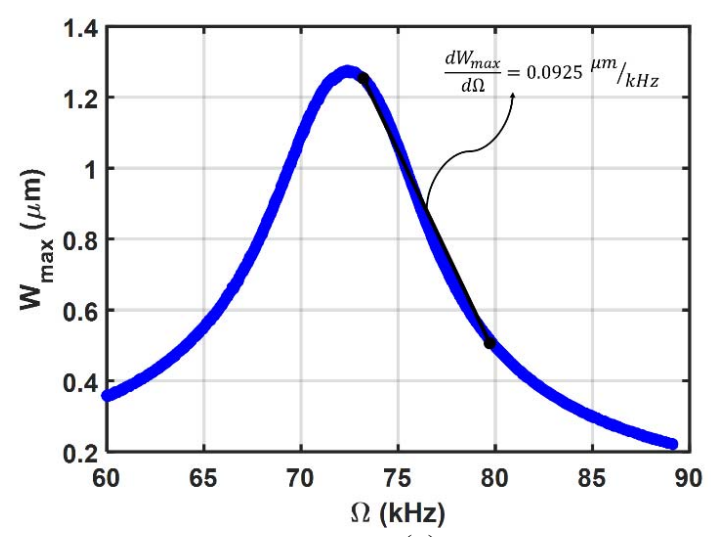

(a)

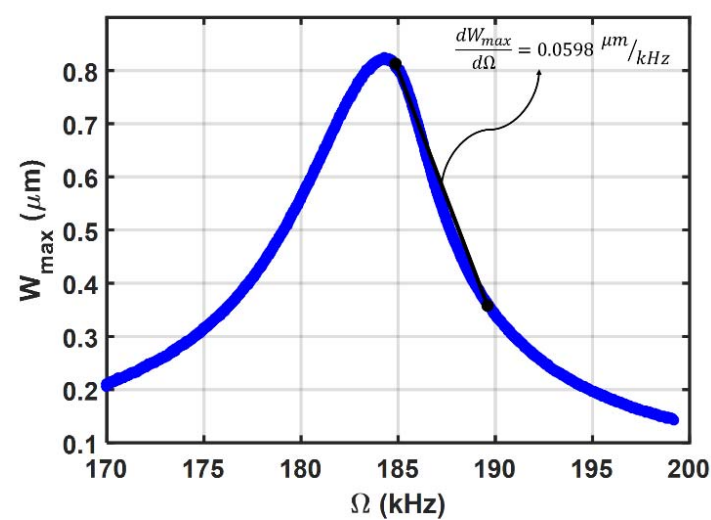

(b)

Fig. 5. The frequency response of the clamped-clamped microbeam at $V_{D C}=30 \mathrm{~V}$ near (a) the first mode and $V_{A C}$ $=35 \mathrm{~V}$, (b) the second mode and $V_{A C}=45 \mathrm{~V}$.

The minimum detectable mass is found by exciting the resonator at the operating frequency and monitoring the amplitude fluctuation due to noise over a 5 minute period. 
The experiment is conducted near the first and second mode of vibration as depicted in Fig. 6. The measured amplitude fluctuation near the first and second mode is $\Delta W_{\max }^{1 s t}=0.02 \mu \mathrm{m} \Delta W_{\max }^{2 n d}=0.019 \mu \mathrm{m}$,

respectively, which correspond to the minimum detectable frequency of $\Delta f_{\min }^{1 s t}=216.2 \mathrm{~Hz}$ and $\Delta f_{\min }^{2 n d}=317.7 \mathrm{~Hz}$, respectively. By utilizing Eq. (1), the minimum detectable mass is $\Delta m_{\mathrm{min}}^{1 s t}=324.3 \mathrm{fg}$ and $\Delta m_{\min }^{2 n d}=203.2 \mathrm{fg}$.

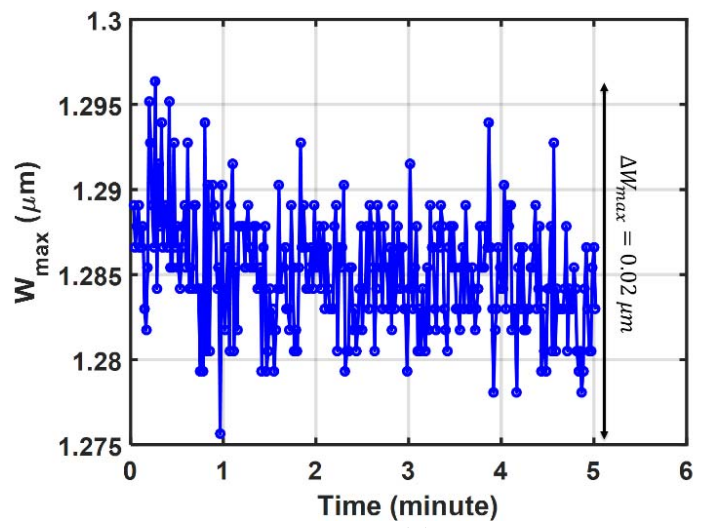

(a)

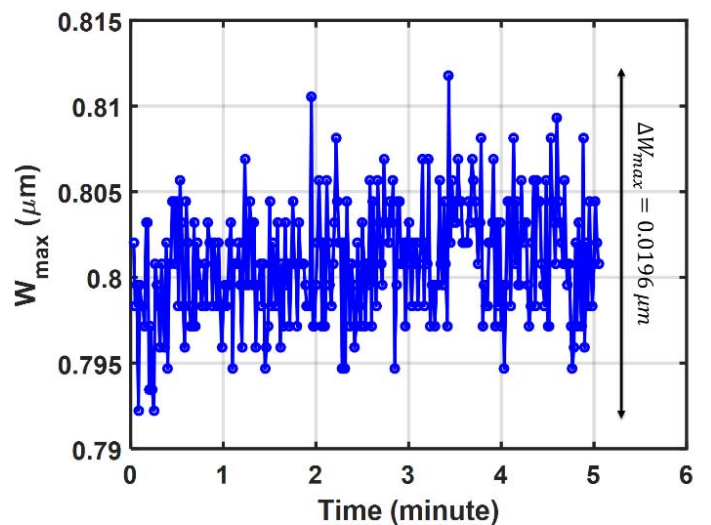

(b)

Fig. 6. The maximum amplitude evolution over time for a fixed frequency excitation at $V_{D C}=30 \mathrm{~V}$ near the (a) first mode, $V_{A C}=35 \mathrm{~V}$, and $\Omega=72.5 \mathrm{kHz}$. (b) Second mode at $V_{A C}=45 \mathrm{~V}$, and $\Omega=184.2 \mathrm{kHz}$.

\section{RESULTS}

The resonator is placed inside the chamber and exposed to water vapor, Acetone, and Ethanol at a fixed flow rate of $4 \mathrm{l} / \mathrm{min}$. The chamber is flushed with nitrogen for an extended period of time until the stabilization of the response. Then, the resonator is exposed to vapors while monitoring the response until saturation, which corresponds to the maximum vapor adsorbed on the resonator surface. To ensure the repeatability of the results, the vapor flow is replaced with nitrogen to flush the resonator and return to the original state. The exposure and flushing cycle is repeated for several times to ensure a complete reversibility of the sensor. Figure 7 shows the frequency shift of the resonator over time due to water vapor, Acetone, and Ethanol exposures near the first and second mode of vibration. A higher frequency shift for the different gasses is reported near the second mode as shown in Table 1. The dynamics of the absorption is studied by fitting an exponentially decaying function $f(t)=\Delta f \exp (-t / \tau$ ) to the experimental data, where $\tau$ is the time constant, and $\Delta f$ is the amplitude of the frequency shift [23]. As shown in Table 1, water vapor has a smaller time constant compared with Acetone, and Ethanol, which indicates a strong affinity of the used MOF to water vapor. The reported results open the door for humidity sensing in wide range of application such as air quality control, process control, and biomedical applications [48].
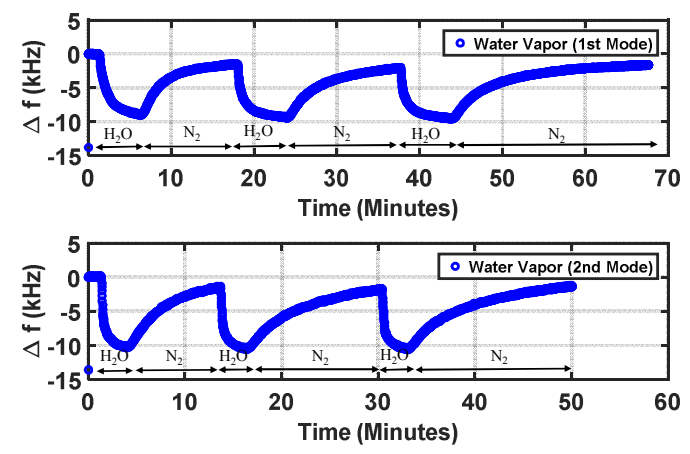

(a)
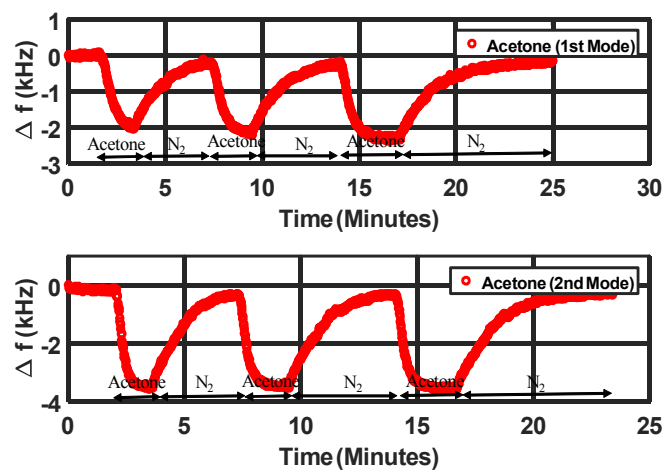

(b)
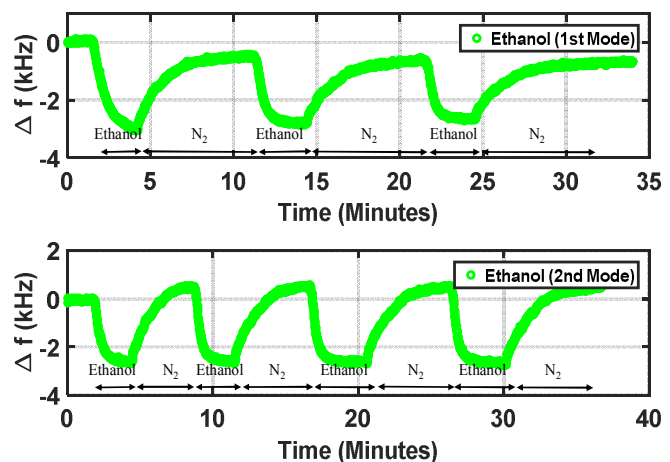

(c)

Fig.7. Real time measurement of the frequency shift near the first and second mode of vibration due to vapor exposures of (a) water vapor, (b) Acetone, and (c) Ethanol.

Table 1. Frequency shifts and the fitted time decay constants due to different gas exposures near the first and second mode of vibration. 


\begin{tabular}{|c|c|c|c|c|}
\hline \multirow{2}{*}{ Gas } & \multicolumn{2}{|c|}{$\begin{array}{c}\text { Frequency shift, } \\
\Delta f(\mathrm{kHz})\end{array}$} & \multicolumn{2}{|c|}{$\begin{array}{c}\text { Decay time } \\
\text { constant, } \tau \text { (min) }\end{array}$} \\
\hline & $\begin{array}{r}1^{s t} \\
\text { mode }\end{array}$ & $\begin{array}{r}2^{\text {nd }} \\
\text { mode }\end{array}$ & $\begin{array}{r}1^{s t} \\
\text { mode }\end{array}$ & $\begin{array}{r}2^{\text {nd }} \\
\text { mode }\end{array}$ \\
\hline $\begin{array}{l}\text { Water } \\
\text { Vapor }\end{array}$ & 7.52 & 8.82 & 0.85 & 1.41 \\
\hline Acetone & 2.15 & 3.24 & 2.21 & 3.34 \\
\hline Ethanol & 1.98 & 2.31 & 2.4 & 2.93 \\
\hline
\end{tabular}

\section{CONCLUSIONS}

We presented a highly sensitive resonant gas sensor, functionalized with uniform MOF layer, and electrostatically excited near the second mode under ambient conditions of pressure and temperature. A minimum detectable mass of $203.2 \mathrm{fg}$ and resolution of $640 \mathrm{ag} / \mathrm{Hz}$ is reported near the second mode of vibration. The resonator is fabricated from polyimide layer which in addition to the stable chemical and thermal properties, has a low modulus of elasticity $(8.5 \mathrm{Gpa})$ which reduces the voltage required to actuate the resonator. Water vapor, Acetone, and ethanol gasses were tested near the first and second mode of vibration where large frequency shift in $(\mathrm{kHz})$ is measured for the first time. The selectivity of the MOF coating to water vapor is demonstrated by studying the adsorption dynamics of the experimentally recorded response.

\section{REFERENCES}

[1] Villarroya, M., Verd, J., Teva, J., Abadal, G., Forsen, E., Murano, F. P., Uranga, A., Figueras, E., Montserrat, J., and Esteve, J., 2006, "System on chip mass sensor based on polysilicon cantilevers arrays for multiple detection," Sensors and Actuators A: Physical, 132(1), pp. 154-164.

[2] Olcum, S., Cermak, N., Wasserman, S. C., and Manalis, S. R., 2015, "High-speed multiple-mode masssensing resolves dynamic nanoscale mass distributions," Nature communications, 6 .

[3] Urbiztondo, M., Peralta, A., Pellejero, I., Sesé, J., Pina, M., Dufour, I., and Santamaria, J., 2012, "Detection of organic vapours with Si cantilevers coated with inorganic (zeolites) or organic (polymer) layers," Sensors and Actuators B: Chemical, 171, pp. 822-831.

[4] Urbiztondo, M., Pellejero, I., Villarroya, M., Sesé, J., Pina, M. P., Dufour, I., and Santamaria, J., 2009, "Zeolitemodified cantilevers for the sensing of nitrotoluene vapors," Sensors and Actuators B: Chemical, 137(2), pp. 608-616.

[5] Lavrik, N. V., and Datskos, P. G., 2003, "Femtogram mass detection using photothermally actuated nanomechanical resonators," Applied Physics Letters, 82(16), pp. 2697-2699.
[6] Forsen, E., Abadal, G., Ghatnekar-Nilsson, S., Teva, J., Verd, J., Sandberg, R., Svendsen, W., Perez-Murano, F., Esteve, J., and Figueras, E., 2005, "Ultrasensitive mass sensor fully integrated with complementary metal-oxidesemiconductor circuitry," Applied Physics Letters, 87(4), p. 043507.

[7] Ilic, B., Czaplewski, D., Craighead, H. G., Neuzil, P., Campagnolo, C., and Batt, C., 2000, "Mechanical resonant immunospecific biological detector," Applied physics letters, 77(3), pp. 450-452.

[8] Ekinci, K., Huang, X., and Roukes, M., 2004, "Ultrasensitive nanoelectromechanical mass detection," Applied Physics Letters, 84(22), pp. 4469-4471.

[9] Jensen, K., Kim, K., and Zettl, A., 2008, "An atomicresolution nanomechanical mass sensor," Nature nanotechnology, 3(9), pp. 533-537.

[10] Chaste, J., Eichler, A., Moser, J., Ceballos, G., Rurali, R., and Bachtold, A., 2012, "A nanomechanical mass sensor with yoctogram resolution," Nature nanotechnology, 7(5), pp. 301-304.

[11] Naik, A., Hanay, M., Hiebert, W., Feng, X., and Roukes, M., 2009, "Towards single-molecule nanomechanical mass spectrometry," Nature nanotechnology, 4(7), pp. 445-450.

[12] Baller, M., Lang, H., Fritz, J., Gerber, C., Gimzewski, J., Drechsler, U., Rothuizen, H., Despont, M., Vettiger, P., and Battiston, F., 2000, "A cantilever array-based artificial nose," Ultramicroscopy, 82(1), pp. 1-9.

[13] Yamagiwa, H., Sato, S., Fukawa, T., Ikehara, T., Maeda, R., Mihara, T., and Kimura, M., 2014, "Detection of volatile organic compounds by weight-detectable sensors coated with metal-organic frameworks," Scientific reports, 4, p. 6247.

[14] Chuang, W.-C., Lee, H.-L., Chang, P.-Z., and Hu, Y.C., 2010, "Review on the modeling of electrostatic MEMS," Sensors, 10(6), pp. 6149-6171.

[15] Younis, M. I., 2011, MEMS Linear and Nonlinear Statics and Dynamics: Mems Linear and Nonlinear Statics and Dynamics, Springer Science \& Business Media.

[16] Sam, J., Kumar, J., Tetteh, E. A., and Braineard, E. P., 2014, "A study of why electrostatic actuation is preferred and a simulation of an electrostatically actuated cantilever beam for mems applications."

[17] Xu, Y., Lin, J.-T., Alphenaar, B. W., and Keynton, R. S., 2006, "Viscous damping of microresonators for gas composition analysis," Applied physics letters, 88(14), p. 143513.

[18] Manzaneque, T., Hernando-García, J., Ababneh, A., Schwarz, P., Seidel, H., Schmid, U., and Sánchez-Rojas, J., 2011, "Quality-factor amplification in piezoelectric 
MEMS resonators applying an all-electrical feedback loop," Journal of Micromechanics and Microengineering, 21(2), p. 025007.

[19] Dennis, J., Ahmed, A., Khir, M. M., and Rabih, A., 2015, "Modelling and Simulation of the Effect of Air Damping on the Frequency and Quality factor of a CMOSMEMS Resonator," Appl. Math. Infor. Sci.(AMIS), 9, pp. 729-737.

[20] Nguyen, V.-N., Baguet, S., Lamarque, C.-H., and Dufour, R., 2015, "Bifurcation-based micro/nanoelectromechanical mass detection," Nonlinear Dynamics, 79(1), pp. 647-662.

[21] Kumar, V., Boley, J. W., Yang, Y., Ekowaluyo, H., Miller, J. K., Chiu, G. T.-C., and Rhoads, J. F., 2011, "Bifurcation-based mass sensing using piezoelectricallyactuated microcantilevers," Applied Physics Letters, 98(15), p. 153510.

[22] Bouchaala, A., Jaber, N., Shekhah, O., Chernikova, V., Eddaoudi, M., and Younis, M. I., 2016, "A smart microelectromechanical sensor and switch triggered by gas," Applied Physics Letters, 109(1), p. 013502.

[23] Hwang, Y., Sohn, H., Phan, A., Yaghi, O. M., and Candler, R. N., 2013, "Dielectrophoresis-assembled zeolitic imidazolate framework nanoparticle-coupled resonators for highly sensitive and selective gas detection," Nano letters, 13(11), pp. 5271-5276.

[24] Hajhashemi, M. S., Rasouli, A., and Bahreyni, B., 2016, "Improving sensitivity of resonant sensor systems through strong mechanical coupling," Journal of Microelectromechanical Systems, 25(1), pp. 52-59.

[25] Gil-Santos, E., Ramos, D., Jana, A., Calleja, M., Raman, A., and Tamayo, J., 2009, "Mass sensing based on deterministic and stochastic responses of elastically coupled nanocantilevers," Nano letters, 9(12), pp. 41224127.

[26] Thiruvenkatanathan, P., Yan, J., Woodhouse, J., and Seshia, A. A., 2009, "Enhancing parametric sensitivity in electrically coupled MEMS resonators," Journal of Microelectromechanical Systems, 18(5), pp. 1077-1086.

[27] Sharos, L., Raman, A., Crittenden, S., and Reifenberger, R., 2004, "Enhanced mass sensing using torsional and lateral resonances in microcantilevers," Applied Physics Letters, 84(23), pp. 4638-4640.

[28] Narducci, M., Figueras, E., Lopez, M. J., Gracia, I., Santander, J., Ivanov, P., Fonseca, L., and Cané, C., 2009, "Sensitivity improvement of a microcantilever based mass sensor," Microelectronic Engineering, 86(4), pp. 11871189.

[29] Lochon, F., Dufour, I., and Rebiere, D., 2005, "An alternative solution to improve sensitivity of resonant microcantilever chemical sensors: comparison between using high-order modes and reducing dimensions,"

Sensors and Actuators B: Chemical, 108(1), pp. 979-985.

[30] Jaber, N., Ramini, A., Carreno, A. A., and Younis, M. I., 2016, "Higher order modes excitation of electrostatically actuated clamped-clamped microbeams: experimental and analytical investigation," Journal of Micromechanics and Microengineering, 26(2), p. 025008.

[31] Dohn, S., Sandberg, R., Svendsen, W., and Boisen, A., 2005, "Enhanced functionality of cantilever based mass sensors using higher modes," Applied Physics Letters, 86(23), p. 233501.

[32] Kadam, A. R., Nordin, G. P., and George, M. A., 2006, "Use of thermally induced higher order modes of a microcantilever for mercury vapor detection," Journal of applied physics, 99(9), p. 094905.

[33] Xu, P., Li, X., Yu, H., and Xu, T., 2014, "Advanced nanoporous materials for micro-gravimetric sensing to trace-level bio/chemical molecules," Sensors, 14(10), pp. 19023-19056.

[34] Wales, D. J., Grand, J., Ting, V. P., Burke, R. D., Edler, K. J., Bowen, C. R., Mintova, S., and Burrows, A. D., 2015, "Gas sensing using porous materials for automotive applications," Chemical Society Reviews, 44(13), pp. 4290-4321.

[35] Alammar, T., Shekhah, O., Wohlgemuth, J., and Mudring, A. V., 2012, "Ultrasound-assisted synthesis of mesoporous $\beta$-Ni $(\mathrm{OH}) 2$ and $\mathrm{NiO}$ nano-sheets using ionic liquids, " Journal of Materials Chemistry, 22 (35), pp. 18252-18260.

[36] Thundat, T., Wachter, E., Sharp, S., and Warmack, R., 1995, "Detection of mercury vapor using resonating microcantilevers," Applied Physics Letters, 66(13), pp. 1695-1697.

[37] Liu, J., Shekhah, O., Stammer, X., Arslan, H. K., Liu, B., Schüpbach, B., Terfort, A., and Wöll, C., 2012, "Deposition of metal-organic frameworks by liquid-phase epitaxy: The influence of substrate functional group density on film orientation, " Materials, 5(9), pp. 15811592.

[38] Shekhah, O., Liu, J., Fischer, R., and Wöll, C., 2011, "MOF thin films: existing and future applications," Chemical Society Reviews, 40(2), pp. 1081-1106.

[39] Homayoonnia, S., and Zeinali, S., 2016, "Design and fabrication of capacitive nanosensor based on MOF nanoparticles as sensing layer for VOCs detection," Sensors and Actuators B: Chemical, 237, pp. 776-786.

[40] Sapsanis, C., Omran, H., Chernikova, V., Shekhah, O., Belmabkhout, Y., Buttner, U., Eddaoudi, M., and Salama, K. N., 2015, "Insights on capacitive interdigitated electrodes coated with MOF thin films: Humidity and 
VOCs sensing as a case study," Sensors, 15(8), pp. 1815318166.

[41] Yassine, O., Shekhah, O., Assen, A. H., Belmabkhout, Y., Salama, K. N., and Eddaoudi, M., 2016, "H2S Sensors: Fumarate-Based fcu-MOF Thin Film Grown on a Capacitive Interdigitated Electrode," Angewandte Chemie International Edition, 55(51), pp. 15879-15883.

[42] Arevalo, A., Byas, E., Conchouso, D., Castro, D., Ilyas, S., and Foulds, I. G., "A versatile multi-user polyimide surface micromachinning process for MEMS applications," Proc. Nano/Micro Engineered and Molecular Systems (NEMS), 2015 IEEE 10th International Conference on, pp. 561-565.

[43] Shekhah, O., Busse, C., Bashir, A., Turcu, F., Yin, X., Cyganik, P., Birkner, A., Schuhmann, W., and Wöll, C., 2006,

"Electrochemically deposited Pd islands on an organic surface: the presence of Coulomb blockade in STM I (V) curves at room temperature, " Physical Chemistry Chemical Physics, 8(29), pp. 3375-3378.

[44] Shekhah, O., and Eddaoudi, M. 2013, "The liquid phase epitaxy method for the construction of oriented ZIF8 thin films with controlled growth on functionalized surfaces," Chemical Communications, 49(86), pp.1007910081.

[45] Streit, H. C., Adlung, M., Shekhah, O., Stammer, X., Arslan, H. K., Zybaylo, O., Ladnorg, T., Gliemann, H., Franzreb, M., Wöll, C., and Wickleder, C., 2012, "Surface-Anchored MOF-Based Photonic Antennae" ChemPhysChem 13(11), pp. 2699-2702.

[46] Boudjiet, M. T., Bertrand, J., Pellet, C., and Dufour, I., 2014, "New characterization methods for monitoring small resonant frequency variation: Experimental tests in the case of hydrogen detection with uncoated silicon microcantilever-based sensors," Sensors and Actuators B: Chemical, 199, pp. 269-276.

[47] Hauer, B. D., Doolin, C., Beach, K. S. D., and Davis, J. P., 2013, "A general procedure for thermomechanical calibration of nano/micro-mechanical resonators," Annals of Physics, 339, pp. 181-207.

[48] Chia-Yen, L., and Gwo-Bin, L., 2003,

"Micromachine-based humidity sensors with integrated temperature sensors for signal drift compensation," Journal of Micromechanics and Microengineering, 13(5), p. 620 .

\section{CONTACT}

Mohammad I. Younis

(Email:mohammad.younis@kaust.edu.sa). 